\title{
REKOMENDASI BENGKEL SEPEDA MOTOR TERBAIK DIKOTA MEDAN BERDASARKAN SURVEY KEPUASAN PELANGGAN DENGAN METODE WEIGHTED SUM MODEL (WSM) BERBASIS GIS
}

\author{
Febri Wijaya Hutagalung ${ }^{1}$, Alfonsus Situmorang², Jimmy F. Naibaho ${ }^{3}$
}

Fakutas Ilmu Komputer

Universitas Methodist Indonesia

\begin{abstract}
The rapid growth of the number of vehicles in the city of Medan is increasing, the growth in the number of vehicles (motorcycles) is proportional to the increase in the number of workshops, both official workshops (official dealers) and unofficial workshops that serve vehicle repairs and sell vehicle spare parts. With the many locations of motorcycle repair shops in the city of Medan, sometimes it makes workshop service users feel confused to find the best workshop location according to the desired criteria. This will cause problems for motorcycle repair service users because not all of them know the name of the workshop and its address, especially for service users who live outside the city of Medan. The purpose of this research is to create a Decision Support System to help repair shop service users make the right decisions. The right method to make it easier for users to choose a motorcycle repair shop is to use method Weigthed Sum Model (WSM) with the help of Google Map. By applying the Weigthed Sum model method, the system built will provide recommendations for the best motorcycle repair shops to potential users of repair services by displaying the location geographically using a Google Map.
\end{abstract}

Keyword : Weigted Sum Model,Workshop Motorcycle, GIS, Survey

\section{PENDAhuluan}

Seiring perkembangan zaman, tingkat mobilitas masyarakat semakin meningkat dari waktu ke waktu. Hal ini menyebabkan pertumbuhan pengguna kendaraan bermotor semakin banyak. Pesatnya pertumbuhan jumlah kendaraan (motor) sebanding dengan bertambahnya jumlah bengkel baik bengkel resmi (dealer resmi) maupun bengkel yang tidak resmi yang melayani perbaikan kendaraan dan menjual peralatan kendaraan. Bengkel merupakan tempat yang tidak sering dikunjungi, tetapi tempat yang paling dibutuhkan saat terjadi kerusakan pada kendaraan.

Pada saat ini, banyak masyarakat masih mengalami kesulitan untuk mencari dan menentukan lokasi bengkel sepeda motor yang tepat, terutama saat mengalami kerusakan di jalan, tentu masyarakat bingung harus pergi ke arah mana untuk mencari bengkel agar memperbaiki kerusakan. Keberagaman bengkel sepeda motor membuat pemilik motor seringkali kesulitan dalam menentukan bengkel sepeda motor yang sesuai dengan kebutuhan dan kriteria yang dibutuhkan sehingga diperlukan suatu aplikasi pendukung keputusan yang dapat membantu pengguna dalam menentukan tempat Bengkel Sepeda Motor yang terbaik sesuai dengan keinginan pemilik motor tersebut.

Penentuan prioritas pemilihan tempat bengkel motor memerlukan data akurat berbasis komputer sebagai dasar pemberian keputusan dalam pemilihan tempat bengkel sepeda motor. Metode Weighted Sum Model (WSM) merupakan salah satu metode penyelesaian yang ditawarkan untuk menyelesaikan masalah Multi Attribute Decision Making (MADM) yang dapat digunakan dalam pengambilan keputusan untuk mencari suatu alternatif terbaik dari berbagai alternatif berdasarkan kriteria kriteria yang telah ditentukan.

Berkembangnya pemanfaatan peta digital dapat memberikan kemudahan bagi masyarakat untuk mengetahui letak lokasi Bengkel Sepeda Motor dengan menggunakan teknologi berbasis visualisai geografis dengan bantuan API Google Map.

\section{TINJAUAN TEORITIS}

\section{Sistem Pendukung Keputusan}

Sistem Pendukung Keputusan (SPK) atau Decision Support System (DSS) adalah sebuah sistem yang mampu memberikan kemampuan pemecahan masalah maupun kemampuan pengkomunikasian untuk masalah dengan kondisi semi terstruktur dan tak terstruktur. Sistem ini digunakan untuk membantu pengambilan keputusan dalam situasi semi terstruktur dan situasi yang tidak terstruktur, dimana tak seorang pun tahu secara pasti bagaimana keputusan seharusnya dibuat.[1]

SPK bertujuan untuk menyediakan informasi, membimbing, memberikan prediksi serta mengarahkan kepada pengguna informasi agar dapat melakukan pengambilan keputusan dengan lebih baik.

Tujuan utama dari pengembangan aplikasi sistem penunjang keputusan (SPK) ini tidak dimaksudkan untuk mengotomatisasikan pengambilan keputusan, tetapi untuk memfasilitasi perangkat interaktif yang digunakan oleh pengambil keputusan untuk melakukan berbagai analisis menggunakan model-model yang tersedia.

1. Sementara itu tujuan detail dari sistem penunjang keputusan adalah sebagai berikut

2. Membantu manajer perusahaan atau organisasi dalam pengambilan keputusan atas masalah semiterstruktur. 
3. Memberikan dukungan atas pertimbangan manager dan bukannya dimaksudkan untuk menggantikan fungsi manager

4. Meningkatkan efektivitas keputusan yang diambil manager lebih dari pada perbaikan efisiensinya.

5. Keputusan komputasi untuk menghasilkan keputusan dengan cepat dan dengan biaya yang rendah.

6. Peningkatan produktivitas. Dengan adanya system ini maka pengguna dapat melakukan beberapa pekerjaan dalam waktu yang hampir bersamaan.

7. Dukungan kualitas. Komputer bisa meningkatkan kualitas yang dibuat.

Berdaya saing. Tekanan persaingan menyebabkan tugas pengambil keputusan menjadi sulit. Teknologi pengambilan keputusan bisa menciptakan pemberdayaan signifikan dengan cara memperbolehkan seseorang untuk membuat keputusan yang baik secara tepat, bahkan jika mereka memiliki pengetahuan yang kurang.

Mengatasi keterbatasan kognitif dalam pemrosesan dan penyimpanan. Otak manusia memiliki kemampuan yang terbatas untuk memproses dan menyimpan informasi. Orang orang kadang sulit mengingat dan menggunakan sebuah informasi dengan cara yang bebas dari kesalahan.

\section{Weigthed Sum Model (WSM)}

Metode WSM merupakan metode MADM (Multiple Attribute Decision Making) yang paling sederhana dan paling banyak digunakan. MADM yaitu suatu metode yang mengambil banyak kriteria sebagai dasar pengambilan keputusan, dengan penilaian yang subjektif menyangkut masalah pemilihan. Metode ini juga metode yang paling mudah untuk diaplikasikan, karena mempunyai algoritma yang tidak terlalu rumit.

Metode Weighted Sum Model juga merupakan metode yang sangat umum, dan banyak diterapkan untuk membantu pengambil keputusan dalam mengambil suatu keputusan. WSM merupakan salah satu metode yang paling sederhana dan mudah dipahami penerapannya.[4] Adapun algoritma dari metode WSM adalah :

1. Identifikasi kriteria dan alternatif yang digunakan dalam penyelesaian masalah

2. Normalisasi nilai alternatif

3. Menghitung nilai WSM-Score menggunakan rumus :

$$
A_{i}^{W S M-s c o r e}=\sum_{j=1}^{n} w_{j} x_{i j}
$$

Dimana :

$\mathrm{n}=$ jumlah kriteria

$\mathrm{wj}=$ bobot dari setiap kriteria

$\mathrm{xij}=$ nilai matrik $\mathrm{x}$

Melakukan perankingan.

\section{PEMBAHASAN}

\section{Analisa Masalah}

Pemilihan bengkel sepeda motor menurut sebagian orang merupakan masalah yang sederhana dan simpel, tetapi ketika dihadapkan dengan banyak pilihan bengkel sepeda motor maka calon pengguna akan merasa kebingungan, dimana setiap bengkel sepeda motor memiliki keunggulan dan kekurangan masing-masing.

Dalam memilih bengkel sepeda motor setiap orang memiliki kriteria kepuasan tersendiri, jika menurut konsumen merasa nyaman dan cocok dengan suatu bengkel sepeda motor, maka tidak perlu lagi melihat-lihat atau mencari informasi tentang bengkel sepeda motor lain. Dalam memilih suatu bengkel sepeda motor tentu saja harus sesuai dengan kriteria calon pengguna bengkel sepeda motor, namun setiap konsumen mempunyai kriteria yang berbeda-beda.

Ada beberapa konsumen yang memilih bengkel sepeda motor dari faktor biaya, atau memilih bengkel sepeda motor karena lokasinya, dan masih banyak lagi contoh lainnya. Dari uraian permasalahan di atas maka dapat disimpulkan masalah yang dihadapi dalam pemilihan bengkel sepeda motor, yaitu :

1. Kesulitan memilih dengan banyak pilihan bengkel sepeda motor.

2. Mencari lokasi terdekat dari posisi konsumen.

3. Mencari layanan yang ada di bengkel sepeda motor.

4. Mencari rute menuju bengkel sepeda motor.

5. Kriteria yang berbeda beda antar konsumen.

\section{Analisa Kriteria}

Dalam penerapan metode ini terdapat beberapa kriteria dan bobot yang diperlukan untuk menentukan Bengkel sepeda motor terbaik. Adapun kriteria yang ditentukan didapat dari hasil kuisioner. Dari data-data tersebut, penulis mengambil beberapa kriteria yang layak untuk digunakan berdasarkan persentase tertinggi.

Pemberian nilai bobot pada masing-masing kriteria didasarkan pada persentase dari total penilaian yang diberikan responden. Sehingga menghasilkan kriteria dan bobot pada tabel 1 .

Tabel 1. Kriteria dan nilai bobot

\begin{tabular}{|l|l|l|}
\hline No. & Nama Kriteria & $\begin{array}{l}\text { Nilai } \\
\text { Bobot } \\
\text { (Wj) }\end{array}$ \\
\hline $\mathbf{1 .}$ & Kebersihan dan kerapian bengkel (C1) & 0,11 \\
\hline $\mathbf{2 .}$ & $\begin{array}{l}\text { Ketersediaan jenis pekerjaan (service, ganti oli, } \\
\text { boring, dll.) (C2) }\end{array}$ & 0,12 \\
\hline $\mathbf{3 .}$ & Kelengkapan alat kerja bengkel (C3) & 0,12 \\
\hline $\mathbf{4 .}$ & $\begin{array}{l}\text { Keramahan dan kesopanan petugas bengkel } \\
\text { (C4) }\end{array}$ & 0,1 \\
\hline $\mathbf{5 .}$ & $\begin{array}{l}\text { Pelayanan petugas bengkel untuk menanggapi } \\
\text { keluhan (C5) }\end{array}$ & 0,09 \\
\hline $\mathbf{6 .}$ & Kewajaran waktu pengerjaan (C6) & 0,11 \\
\hline $\mathbf{7 .}$ & $\begin{array}{l}\text { Kewajaran biaya yang dikeluarkan dengan hasil } \\
\text { perbaikan (C7) }\end{array}$ & 0,11 \\
\hline $\mathbf{8 .}$ & Kualitas hasil pengerjaan sepeda motor (C8) & 0,12 \\
\hline $\mathbf{9 .}$ & Ketersediaan suku cadang atau sparepart (C9) & 0,12 \\
\hline
\end{tabular}

Dari kriteria tersebut, maka dibuat suatu tingkat kepentingan kriteria berdasarkan nilai bobot yang telah 
ditentukan. Nilai tingkat kepentingan kriteria tersebut terdapat pada tabel berikut.

Tabel 2. Tingkat Kepentingan kriteria

\begin{tabular}{|l|l|l|}
\hline 1 & Penilaian & Nilai \\
\hline 1. & Sangat Baik & 1 \\
\hline 2. & Baik & 0,75 \\
\hline 3. & Cukup Baik & 0,5 \\
\hline 4. & Buruk & 0,25 \\
\hline 5. & Sangat Buruk & 0 \\
\hline 6. & Sangat Murah & 1 \\
\hline 7. & Murah & 0,75 \\
\hline 8. & Standar & 0,5 \\
\hline 9. & Mahal & 0,25 \\
\hline 10. & Sangat Mahal & 0 \\
\hline
\end{tabular}

\section{Proses Perhitungan dengan Metode Weigthed Sum Model (WSM)}

Untuk mendapatkan rekomendasi bengkel sepeda motor terbaik, maka dilakukan proses perhitungan dengan metode Weighted Sum Model(WSM) yang membutuhkan nilai bobot dari masing-masing kriteria serta nilai matrik $\mathrm{x}$, dimana nilai matrik $\mathrm{x}$ didapatkan dari hasil penilaian responden. Penilaian responden dapat dilihat pada tabel 3. Data alternatif yang digunakan adalah 5 data bengkel sepeda motor yang diambil secara acak dari banyaknya bengkel sepeda motor yang ada di Kota Medan.

Tabel 3. Penilaian Responden

\begin{tabular}{|l|l|l|l|l|l|l|}
\hline No. & $\begin{array}{l}\text { Krite } \\
\text { ria }\end{array}$ & $\begin{array}{l}\text { MPM } \\
\text { Motor } \\
\text { Honda }\end{array}$ & $\begin{array}{l}\text { Honda } \\
\text { AHAS } \\
\begin{array}{l}\text { Lamlo } \\
\text { Servis }\end{array}\end{array}$ & $\begin{array}{l}\text { Bengkel } \\
\text { Honda } \\
\text { Jaya } \\
\text { Latun }\end{array}$ & $\begin{array}{l}\text { Yogi } \\
\text { Servis }\end{array}$ & $\begin{array}{l}\text { Honda } \\
\text { Ahas } \\
9076\end{array}$ \\
\hline 1. & C1 & $\begin{array}{l}\text { Sangat } \\
\text { Baik }\end{array}$ & $\begin{array}{l}\text { Sangat } \\
\text { Baik }\end{array}$ & Baik & $\begin{array}{l}\text { Sangat } \\
\text { Baik }\end{array}$ & $\begin{array}{l}\text { Sangat } \\
\text { Baik }\end{array}$ \\
\hline 2. & C2 & Baik & Baik & Baik & Baik & $\begin{array}{l}\text { Sangat } \\
\text { Baik }\end{array}$ \\
\hline 3. & C3 & $\begin{array}{l}\text { Cukup } \\
\text { Baik }\end{array}$ & Baik & $\begin{array}{l}\text { Cukup } \\
\text { Baik }\end{array}$ & Buruk & $\begin{array}{l}\text { Sangat } \\
\text { Baik }\end{array}$ \\
\hline 4. & C4 & $\begin{array}{l}\text { Cukup } \\
\text { Baik }\end{array}$ & $\begin{array}{l}\text { Sangat } \\
\text { Baik }\end{array}$ & Baik & $\begin{array}{l}\text { Cukup } \\
\text { Baik }\end{array}$ & $\begin{array}{l}\text { Sangat } \\
\text { Baik }\end{array}$ \\
\hline 5. & C5 & $\begin{array}{l}\text { Sangat } \\
\text { Baik }\end{array}$ & Baik & Baik & $\begin{array}{l}\text { Sangat } \\
\text { Baik }\end{array}$ & $\begin{array}{l}\text { Sangat } \\
\text { Baik }\end{array}$ \\
\hline 6. & C6 & Baik & $\begin{array}{l}\text { Sangat } \\
\text { Baik }\end{array}$ & Baik & Buruk & $\begin{array}{l}\text { Sangat } \\
\text { Baik }\end{array}$ \\
\hline 7. & C7 & $\begin{array}{l}\text { Cukup } \\
\text { Murah }\end{array}$ & Murah & Murah & $\begin{array}{l}\text { Cukup } \\
\text { Murah }\end{array}$ & $\begin{array}{l}\text { Sangat } \\
\text { Baik }\end{array}$ \\
\hline 8. & C8 & $\begin{array}{l}\text { Sangat } \\
\text { Baik }\end{array}$ & Baik & Baik & $\begin{array}{l}\text { Cukup } \\
\text { Baik }\end{array}$ & $\begin{array}{l}\text { Sangat } \\
\text { Baik }\end{array}$ \\
\hline 9. & C9 & $\begin{array}{l}\text { Cukup } \\
\text { Baik }\end{array}$ & $\begin{array}{l}\text { Sangat } \\
\text { Baik }\end{array}$ & Baik & Baik & $\begin{array}{l}\text { Sangat } \\
\text { Baik }\end{array}$ \\
\hline
\end{tabular}

Tabel 4. Hasil Konversi Penilaian Responden

\begin{tabular}{|c|c|c|c|c|c|c|}
\hline No & $\begin{array}{l}\text { Kriteri } \\
\text { a }\end{array}$ & $\begin{array}{l}\text { MPM } \\
\text { Moto } \\
r \\
\text { Hond } \\
\text { a } \\
\end{array}$ & $\begin{array}{l}\text { Honda } \\
\text { AHAS } \\
\text { S } 1458 \\
\text { Lamlo } \\
\text { Servis }\end{array}$ & $\begin{array}{l}\text { Bengk } \\
\text { el } \\
\text { Honda } \\
\text { Jaya } \\
\text { Latun }\end{array}$ & $\begin{array}{l}\text { Yogi } \\
\text { Servi } \\
\text { s }\end{array}$ & $\begin{array}{l}\text { Hond } \\
\text { a } \\
\text { Ahas } \\
9076\end{array}$ \\
\hline 1. & $\mathrm{C} 1$ & 1 & 1 & 0.75 & 1 & 1 \\
\hline 2. & $\mathrm{C} 2$ & 0.75 & 0.75 & 0.75 & 0.75 & 1 \\
\hline
\end{tabular}

\begin{tabular}{|l|l|l|l|l|l|l|}
\hline 3. & C 3 & 0.5 & 0.75 & 0.5 & 0.25 & 1 \\
\hline 4. & C4 & 0.5 & 1 & 0.75 & 0.5 & 1 \\
\hline 5. & C5 & 1 & 0.75 & 0.75 & 1 & 1 \\
\hline 6. & C6 & 0.75 & 1 & 0.75 & 0.25 & 1 \\
\hline 7. & C7 & 0.5 & 0.75 & 0.75 & 0.5 & 1 \\
\hline 8. & C 8 & 1 & 0.75 & 0.75 & 0.5 & 1 \\
\hline 9. & C9 & 0.5 & 1 & 0.75 & 0.75 & 1 \\
\hline
\end{tabular}

enilaian yang diberikan oleh masing-masing responden akan dikonversi ke dalam bentuk angka (tingkat kepentingan kriteria). Tabel tersebut dapat dilihat pada tabel 4 diatas.

Kemudian menghitung nilai WSM Score :

MPM Motor Honda $=(0.11 * 1)+(0.12 * 0.75)+(0.12 *$ $0.5)+(0.1 * 0.5)+(0.09 * 1)+(0.11 * 0.75)+(0.11 * 0.5)$ $+(0.12 * 1)+(0.12 * 0.5)$

$=0,7175$

Honda AHASS 1458 Lamlo Servis $=(0.11 * 1)+(0.12 *$ $0.75)+(0.12 * 0.75)+(0.1 * 1)+(0.09 * 0.75)+(0.11 *$ $1)+(0.11 * 0.75)+(0.12 * 0.75)+(0.12 * 1)$

$=0,86$

Bengkel Honda Jaya Latun $=(0.11 * 0.75)+(0.12 * 0.75)$ $+(0.12 * 0.5)+(0.1 * 0.75)+(0.09 * 0.75)+(0.11 * 0.75)$ $+(0.11 * 0.75)+(0.12 * 0.75)+(0.12 * 0.75)$

$=0,72$

Yogi Servis $=(0.11 * 1)+(0.12 * 0.75)+(0.12 * 0.25)+$ $(0.1 * 0.5)+(0.09 * 1)+(0.11 * 0.25)+(0.11 * 0.5)+$ $(0.12 * 0.5)+(0.12 * 0.75)$

$=0,6025$

Honda Ahas $9075=(0.11 * 1)+(0.12 * 1)+(0.12 * 1)+$ $(0.1 * 1)+(0.09 * 1)+(0.11 * 1)+(0.11 * 1)+(0.12 * 1)$ $+(0.12 * 1)$

$=1$

Tabel 5. Hasil Ranking

\begin{tabular}{|l|l|l|l|}
\hline No. & Alternatif & Hasil & Ranking \\
\hline 1. & MPM Motor Honda & 0,7175 & 4 \\
\hline 2. & $\begin{array}{l}\text { Honda AHASS 1458 } \\
\text { Lamlo Servis }\end{array}$ & 0.86 & 2 \\
\hline 3. & $\begin{array}{l}\text { Bengkel Honda Jaya } \\
\text { Latun }\end{array}$ & 0.72 & 3 \\
\hline 4. & Yogi Servis & 0.6025 & 5 \\
\hline 5. & Honda AHASS 9075 & 1 & 1 \\
\hline
\end{tabular}

Berdasarkan hasil perhitungan menggunakan metode WSM dari survey responden maka didapatlah nilai ranking terbesar pada Honda AHASS 9075. Maka rekomendasi bengkel sepeda motor terbaik berdasarkan hasil survey pelanggan yang akan direkomendasikan kepada pengguna sepeda motor dalam melakukan perbaikan sepeda motor adalah bengkel sepeda motor Honda AHASS 9075, kemudian bengkel Honda AHASS 1458 Lamlo Servis, Bengkel Honda Jaya Latun, MPM Motor Honda dan terakhir Yogi Servis. 


\section{Perancangan Sistem}

Perancangan merupakan penggambaran, perencanaan dan pembuatan sketsa yang bertujuan untuk melakukan tahap awal dalam pengembangan setelah melakukan analisa kemudian difokuskan pada suatu bentuk perencanaan. Adapun bentuk-bentuk perencanaan tersebut adalah use case diagram, activity diagram, sequence dan class diagram serta table-tabel database [3]. Perancangan sistem secara umum dilakukan dengan menggunakan UML (Unified Modeling Languange). Dalam membangun aplikasi, penulis menggunakan 4 jenis diagram, yaitu use case diagram, activity diagram, sequence diagram dan class diagram.

\section{Use Case Diagram}

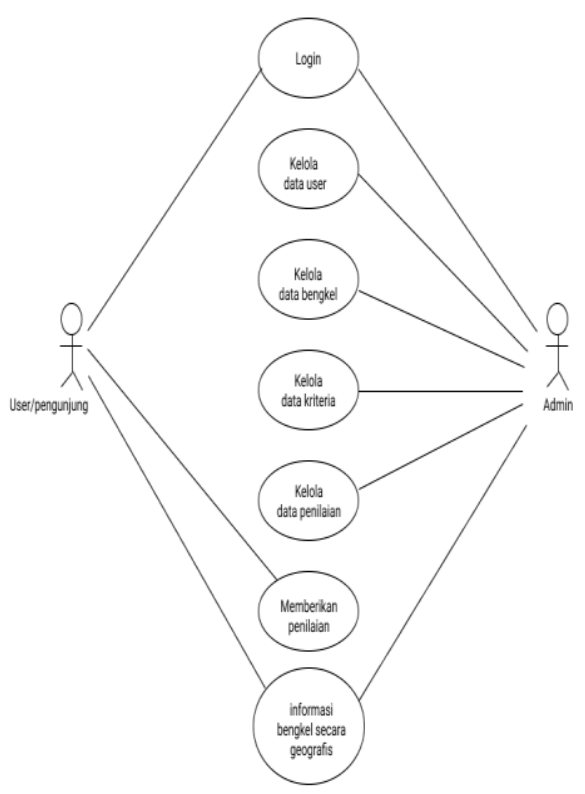

Gambar 1. Use Case Diagram

\section{Activity Diagram}

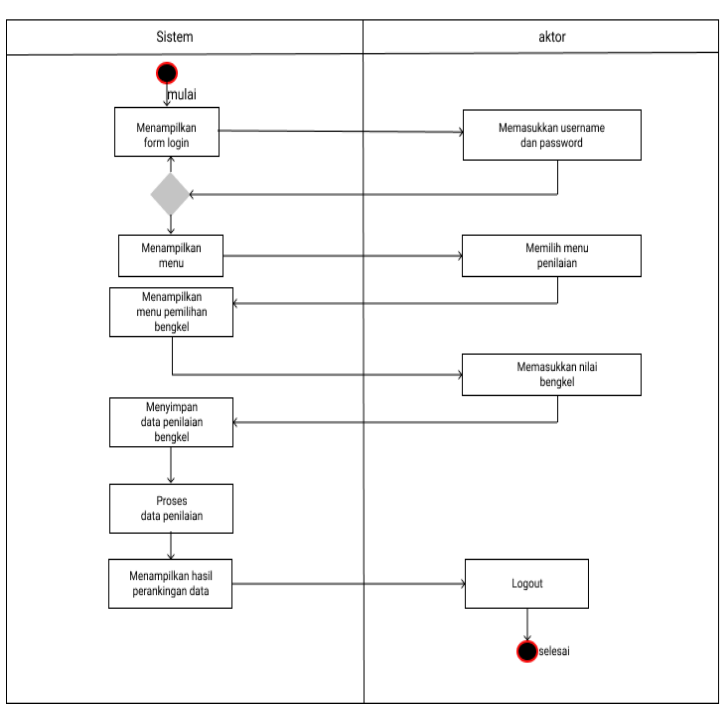

Gambar 2. Activity Diagram

\section{Sequence Diagram}

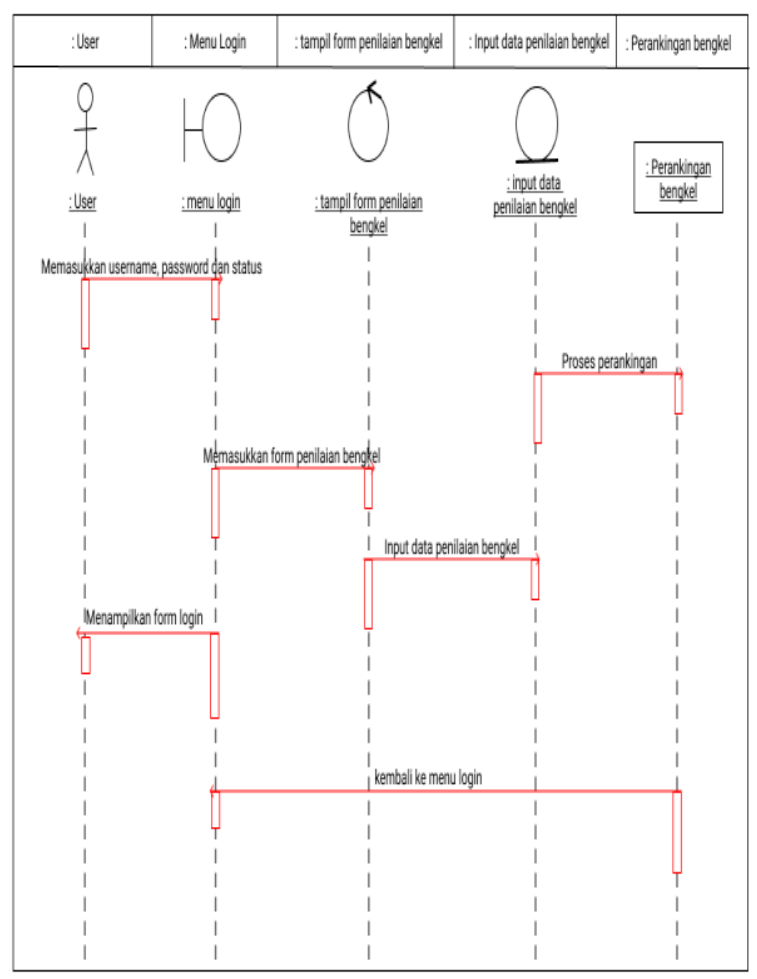

Gambar 3. Sequence Diagram

\section{Class Diagram}

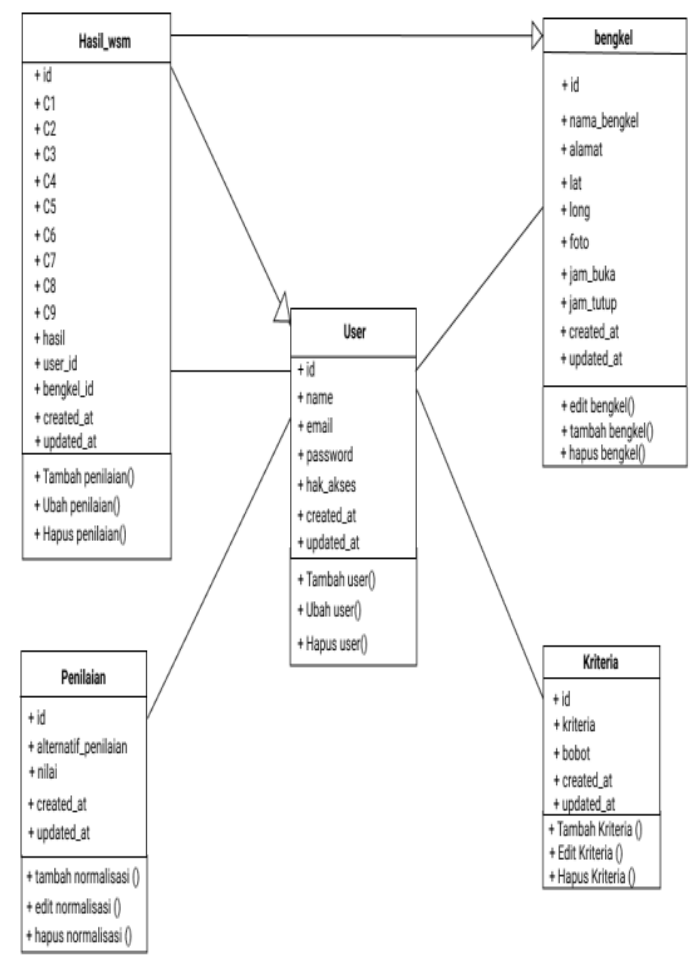

Gambar 4. Class Diagram 


\section{HASIL DAN PENGUJIAN}

\section{Pengertian Implementasi Sistem}

Implementasi sistem adalah langkah-langkah atau prosedur yang dilakukan dalam menyelesaikan desain sistem yang telah disetujui, menguji, dan memulai sistem baru yang telah disempurnakan. [2]

\section{Komponen Utama dalam Implementasi Sistem}

Agar sistem perancangan yang telah dikerjakan dapat berjalan baik atau tidak, maka diperlukan pengujian terhadap sistem yang telah dikerjakan. Oleh karena itu, dibutuhkan beberapa komponen untuk mencakup perangkat keras (Hardware), perangkat lunak (Software), dan perangkat manusia (Brainware).

\section{Perangkat Keras (Hardware)}

Hardware atau yang lebih dikenal dengan sebutan perangkat keras adalah semua jenis komponen yang ada pada komputer yang mana bagian fisiknya dapat terlihat secara kasat mata atau dapat dirasakan secara langsung. Jadi bisa dikatakan jika hardware adalah peralatan fisik komputer yang berguna untuk melakukan proses input, proses, dan output. Perangkat keras yang digunakan meliputi: Monitor, Processor, Hardisk sebagai tempat sistem beroperasi dalam media penyimpanan, RAM, Keyboard dan Mouse.

\section{Perangkat Lunak (Software)}

Software atau perangkat lunak merupakan jembatan penghubung yang menghubungkan antara pengguna dengan hardware sehingga dapat melakukan suatu perintah tertentu. Dalam hal ini perangkat lunak yang digunakan adalah :Operating System Windows 10, Visual Studio Code sebagai tools editor untuk membuat website, Xатpp v.3.2.4, dimana terdapat Apache sebagai web server, PHP sebagai Bahasa pemrograman yang digunakan, serta MYSQL sebagai software untuk server database, Laravel 7, sebagai framework PHP untuk untuk perancangan aplikasi web yang cepat dan mudah, Google Chrome Versi 90.0.4430.93, untuk menjalankan program yang telah dirancang.

\section{Unsur Manusia (Brainware)}

Brainware adalah istilah yang digunakan untuk manusia yang berhubungan dengan sistem komputer. Faktor manusia yang dimaksud adalah orang-orang yang memiliki bagian untuk menangani sistem dan merupakan unsur manusia yang meliputi : Analisa Sistem, adalah adalah seseorang yang bertanggung jawab atas penelitian, perencanaan, pengkoordinasian, dan merekomendasikan pemilihan perangkat lunak dan sistem yang paling sesuai dengan kebutuhan organisasi bisnis atau perusahaan. Programmer adalah jenis profesi atau pekerjaan yang bertujuan untuk membuat sebuah sistem menggunakan bahasa pemrograman. Operator (Administrator), yaitu orang yang mengoperasikan sistem seperti memasukkan data untuk dioperasikan oleh komputer dalam menghasilkan informasi dan lain sebagainya.

\section{Tampilan Program}

\section{Tampilan Login}

Pada Form dibawah ini adalah form yang berfungsi untuk masuk ke halaman home website bagi pengguna biasa dan ke halaman admin untuk mengelola data. Seorang admin maupun user yang ingin masuk harus diwajibkan untuk memberikan username dan password yang benar. Apabila admin atau user tidak menginput data username dan password yang valid, maka admin atau user tidak bisa masuk ke halaman masing-masing dan akan terdapat pemberitahuan bahwa username dan password yang diberikan tidak valid.

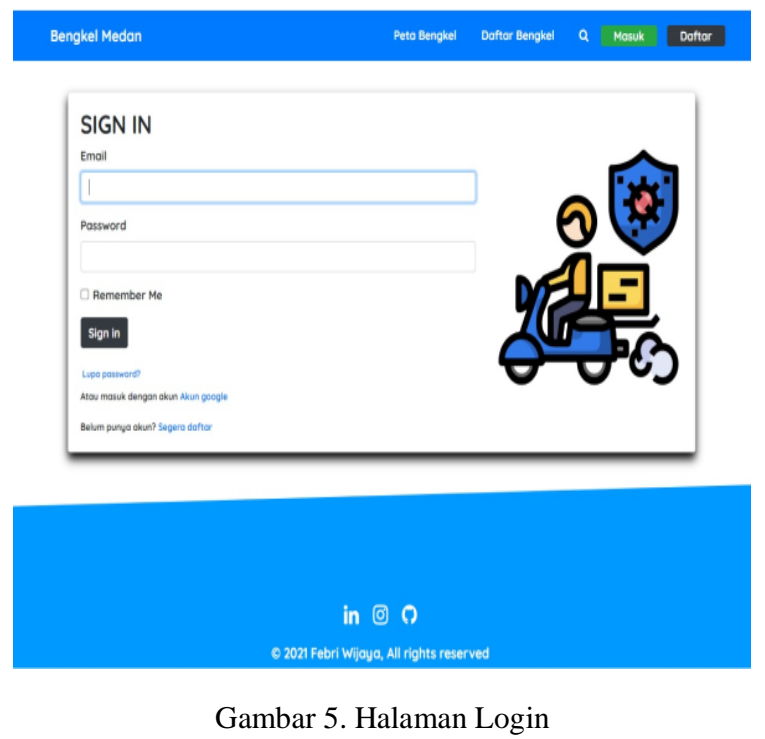

Tampilan Registrasi User

Gambar dibawah ini merupakan tampilan gambar untuk mendaftarkan pengguna baru. Untuk form penginputan data user, terdapat data data yang wajib diisi oleh seorang user, yaitu username, password, dan konfirmasi password.

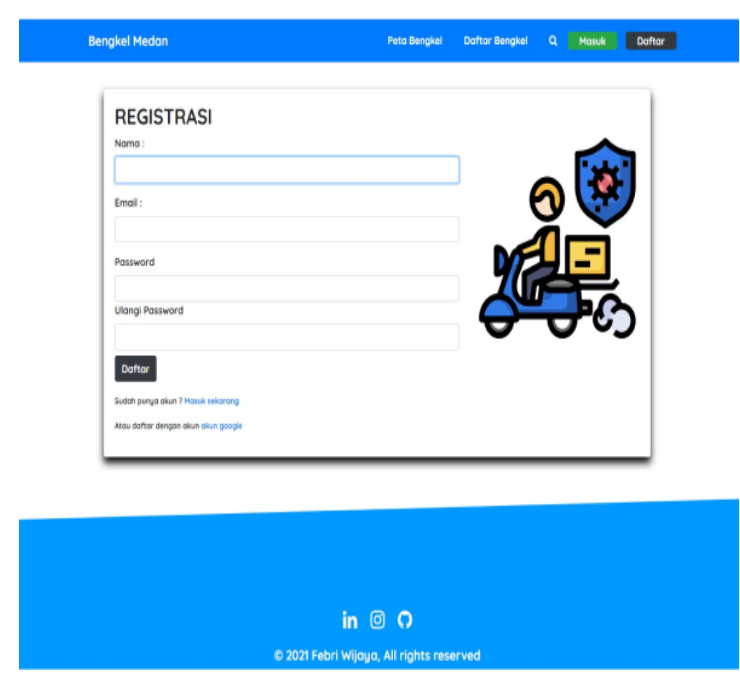

Gambar 6. Halaman Registrasi

\section{Tampilan Dashboard Admin}

Gambar dibawah ini merupakan tampilan gambar yang menunjukkan informasi banyaknya jumlah data dari 
masing-masing tabel serta menu-menu untuk mengelola data bengkel, kriteria, penilaian, hasil WSM, dan data user.

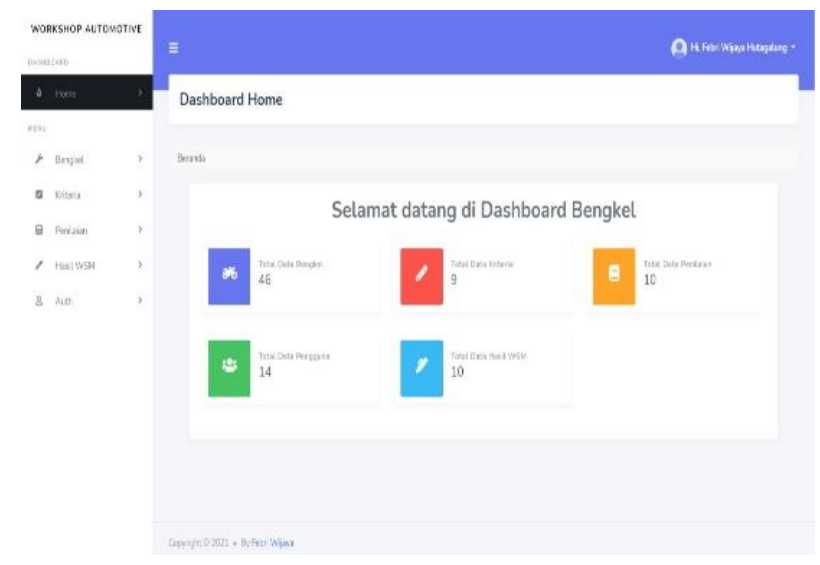

Gambar 7. Halaman Dashboard

\section{Tampilan Utama}

Pada gambar dibawah ini menampilkan halaman utama sistem yang telah dibuat. Halaman ini menampilkan daftar bengkel sepeda motor yang telah diinput ke dalam database, daftar bengkel sepeda motor terbaik dan terdekat dengan menggunakan metode WSM.

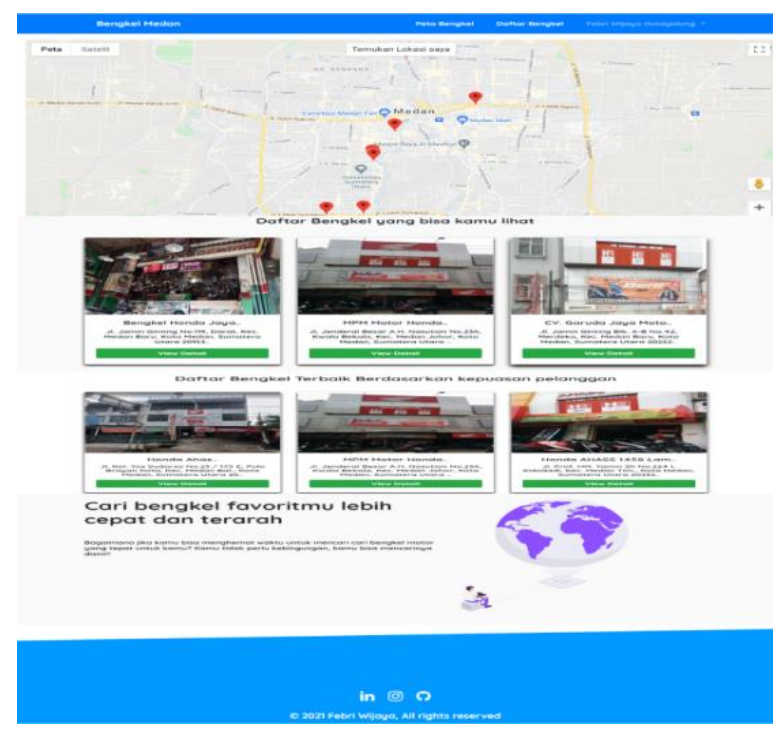

Gambar 8. Halaman Utama

\section{KESIMPULAN}

Adapun kesimpulan dari penelitian ini adalah Aplikasi sistem pendukung keputusan menerapkan metode WSM untuk memudahkan calon pengunjung dalam mengambil keputusan terhadap pemilihan bengkel sepeda motor terbaik. Sistem ini hanya menjadi alat bantu bagi pengambil keputusan, keputusan akhir tetap berada ditangan pengambil keputusan, Proses dari penentuan rangking pemilihan bengkel sepeda motor dilakukan dengan menggunakan metode Weighted Sum Model (WSM), dimulai dengan pembobotan kriteria, melakukan perhitungan dengan metode WSM, dan terakhir pengurutan ranking, Dengan menerapkan metode WSM dari survey responden maka akan didapatkan rekomendasi bengkel sepeda motor terbaik. Berdasarkan hasil perankingan, yang menjadi rekomendasi adalah Bengkel Honda AHASS 9075.

\section{DAFTAR PUSTAKA}

[1] A. Kurniawan, "Sistem Pendukung Keputusan," 5 Juni 2021. [Online]. Available: https://www.gurupendidikan.co.id/sistem pendukungkeputusan/

[2] B. Hutauruk, B. D., Naibaho, J. F., \& Rumahorbo, "Analisis Dan Perancangan Aplikasi Marketplace Cinderamata Khas Batak Berbasis Android," J. Method., vol. 3, no. 1, pp. 242-246, 2017

[3] D. Gustina and andika yunianto, "Rancang Bangun Aplikasi Sistem Informasi Jasa Service Sepeda Motor Berbasis Web (Studi Kasus : PT. Lancar Sukses Mandiri)," vol. 20, no. 1, 2019, doi: 10.31219/osf.io/27sy8

[4] M. Mesran, S. Suginam, S. D. Nasution, and A. P. U. Siahaan, "Penerapan Weighted Sum Model (WSM) Dalam Penentuan Peserta Jaminan Kesehatan Masyarakat," Jurasik (Jurnal Ris. Sist. Inf. dan Tek. Inform., vol. 2, no. 1, p. 40, 2017, doi: 10.30645/jurasik.v2i1.17. 